\title{
Factors Leading to a Dramatic Fall in Coronary Heart Disease Death Rates in Los Angeles County
}

\author{
L. Julian Haywood \\ University of Southern California School of Medicine, Los Angeles, CA, USA \\ Email: jHaywood@usc.edu
}

How to cite this paper: Haywood, L.J. (2018) Factors Leading to a Dramatic Fall in Coronary Heart Disease Death Rates in Los Angeles County. World Journal of Cardiovascular Diseases, 8, 229-235. https://doi.org/10.4236/wjcd.2018.83022

Received: January 19, 2018

Accepted: March 26, 2018

Published: March 29, 2018

Copyright $\odot 2018$ by author and Scientific Research Publishing Inc. This work is licensed under the Creative Commons Attribution International License (CC BY 4.0).

http://creativecommons.org/licenses/by/4.0/

\begin{abstract}
This paper provides commentary on some of the factors leading to a dramatic fall in heart disease death rates and the 42-year period (1968-2010) documented on the accompanying table.
\end{abstract}

\section{Keywords}

Coronary Heart Disease, Mortality Rates, Coronary Care Unit

\section{Introduction}

Los Angeles County, similar to the rest of the State and Country, was in the midst of an epidemic of coronary heart disease deaths in the late fifties and early sixties. Dr. Weldon Walker, attending cardiologist on the CME (College of Medical Evangelists) faculty (now a component of the Loma Linda University), felt that high rates of smoking were a major factor, while the Los Angeles Chapter of the American Heart Association also emphasized high cholesterol diets and high blood pressure [1].

Prominent among the recognized elements was the high rates of heart attacks and the high rate of death occurring both before and after victims could reach hospitals. High hospital death rates occurred because hospitals were not prepared to take proper care after patient arrival.

Multiple efforts were made to address individual components of this problem in various parts of the country and abroad, as the problem extended to most developed countries as well.

Sudden death due to cardiac arrest led to efforts to develop an electrical defibrillator and to organized efforts to develop means of cardiorespiratory resusci- 
tation and life support wherever the event might occur, and a recognition that such skills should be taught to trained responders charged with arriving to render aid and provide transport to hospitals [2].

In Los Angeles, volunteers collaborating through the Heart Association, led by Dr. Walter Graf and later Michael Criley, spearheaded a successful effort to establish training and standardization for personnel of the Los Angeles Fire Department [3].

Early recognition of the high death rate from heart attacks (acute myocardial infarction) led to a randomized multicenter trial of anticoagulation of acute heart attack victims organized by Drs. Bearman and Bierman of the University of Minnesota based on the theory that dissolution of the acute clot obstruction of a clogged coronary artery would improve chances of the victim's survival. However results of using heparin, warfarin or a combination showed no benefit compared to placebo [4].

One of the investigators in that trial, however, Dr. Lawrence Melchior of Philadelphia Women's Hospital, using ECG machines, found evidence that deleterious arrhythmias were the likely mechanisms of in-hospital death. Dr. Morris Wilbourne in Los Angeles proposed the idea of a special cardiac care unit to closely monitor heart attack patients [5].

Dr. Hughes Day of Kansas City soon after reported that a special unit set up in a hospital to monitor heart attack victims could indeed document such sudden life-threatening arrhythmias and effectively treat some leading to a reduction in in-hospital death rates.

Dr. Samuel Fox, assisted by Dr. Edward Cross, noting those signs of progress in addressing the heart attack death rate problem began a program of pilot project support for the US Public Health. Department in Washington, encouraging clinicians to develop acute care units such as the one described by Hughes Day in hospitals across the country.

Dr. Julian Haywood, now a cardiologist on the staff of the Los Angeles County Hospital and junior faculty member of USC School of Medicine and Loma Linda, having spent two years training at White Memorial Hospital and participating with Dr. Donald Griggs in the anticoagulation trial of Bearman and Bierman, traveled to Washington, DC, with a fellow former resident of LA County Hospital and cardiology fellow at USC under Drs. David Blankenhorn and Max H. Weil (Dr. Milford Wyman), at personal expense, to meet with Drs. Fox and Cross (a Haywood classmate) and received assurances that support would be made available to help facilitate development of a Coronary Care Demonstration Unit at the LA County Hospital at which personnel could be trained to staff such units at hospitals throughout the County.

Returning to Los Angeles, Dr. Haywood received support from the USC Department of Medicine and the LA County Hospital Administration to build a four-bed demonstration unit in an existing ward area and assurance that if it proved successful a larger facility would follow. Dr. Haywood also received 
prompt support from the LA Heart Association to support nursing personnel to staff the Unit and participate in the training of RN staff from other hospitals which opened their own units.

During the interim period, a survey was carried out of all hospitals treating heart attack patients to assess the latest annual death rates. All hospitals treating significant numbers of patients reported high mortality rates, including the Los Angeles County Hospital which reported an overall rate of $45 \%$ and when cases unlikely to be eligible for a coronary care unit were eliminated the rate was still $33 \%-35 \%$. The results of the survey were published. Dr. Wyman established a unit at San Pedro Hospital in 1965 [6].

The Demonstration Unit opened in October, 1966 and with the resulting efforts to establish coronary care units proceeding among area hospital an effort began within the Los Angeles Heart Association to establish standards for certifying hospitals that had coronary care units that met standards and emergency departments that were prepared to receive heart attack patients and expedite their treatment according to newly established guidelines.

Hospitals which met the new standards were able to display a prominent sign outside the Emergency entrance which informed the public and emergency personnel of the availability of appropriate services and encouraged by passing of hospitals that did not meet standards.

Besides the immediate effects of the improved care which the development of coronary care units provided, there were parallel efforts in several directions and development of new and re = doubled investigative programs [7].

\section{CCU}

Among the new developments related directly to the CCU were improvements in the defibrillators, in particular those by Bernard Lown, M.D., and by various equipment makers [8].

Dr. Julian Haywood and his colleagues developed a digital method of heart rhythm monitoring which was adapted by industry and which quickly replaced the labor intensive analogue systems which required constant human attention [9].

Dr. Thomas Killip described a practical system of patient assessment that came to be known as the Killip classification, with four degrees of severity. Dr. Killip also developed a small, braided wire which could be threaded intravenously into the right heart to treat acute AV block. He initially advocated doing this for every patient but evidence quickly accumulated casting doubt on this need and the practice was abandoned except for selected patients [10].

On the other hand, the use of right-sided hemodynamic assessment of sicker patients to treat heart failure complications was shown to be useful by multiple investigators and the development of a balloon-tipped catheter by Jeremy Swan and Willie Ganz proved to be highly practical and was quickly adapted by clinicians, including a special model with an electrode component to be used for car- 
diac pacing in selected patients [11].

The National Heart Institute in Bethesda, MD, promulgated an RFP inviting investigators to apply for grants to support research involving improved care for heart attack victims and five projects were initially approved a unit located at Cedar-Sinai Medical Center in Los Angeles was approved later. These units came to be known as the MIRUs (Myocardial Infarction Research Units) [12].

\section{Other Cardiac Developments}

In quick order, the practicality of performing coronary angiography on suspected heart attack patients was soon demonstrated in Spokane, WA, by a former Los Angeles County Hospital intern, who had further training at Cedar Sinai. A practical approach was demonstrated by Mason Sones, M.D. Of Milwaukee, which lead to research on direct clot resolution and to various forms of mechanical correction including bypass surgery and intracoronary (PTCA) balloon opening of obstruction [13].

Incremental improvements in all of the above areas have been made in the ensuing years, all contributing to improved management of suspected heart attack subjects and their post-hospitalization management.

The effectiveness of beta-blocker therapy in reducing the post myocardial infarction death rate and reducing the rate of recurrent heart attacks was demonstrated in an NIH-sponsored clinical trial partially conducted at the LA County Hospital (Dr. Haywood principle investigator).

Strongly contributing to the overall coronary heart disease death rate has been contributions made to controlling risk factors. Prominent in this area has been progress in treating high blood pressure, including the development of new and effective anti-hypertensive drugs. Besides salt restriction, bed rest and sedatives, the new era of effective drug management came about with the appearance of ganglionic blocking agents such as hexamethonium-familiarly known as "C6", I first encountered this drug as an intern in 1952-53 when a Georgetown attending physician, Frank Finerty, a colleague of Dr. Edward Fries of the Washington D.C. VA Hospital, came to St. Mary's Hospital in Rochester, NY, to do teaching rounds. A hypertensive female gave consent to try this new drug which when titrated intravenously lowered her systolic pressure by $50 \mathrm{mmHg}$ within a few minutes. This and similar potent drugs were difficult to manage in oral form but nevertheless were the forerunners of more effective similar drugs, diuretics, etc. [14].

The local American Heart Association (John Chapman, Ph.D.) demonstrated the remarkable differences in the rates of cardiac disease mortality and morbidity among race-ethnic groups in Los Angeles and the need for resources to address the associated needs for programs and services, with dramatically higher rates of stroke in African Americans.

Indeed a dramatic moment in medicine occurred when Dr. R.H. Smithwick, the developer of the surgical procedure of ganglionic blockade of varying de- 
grees, appeared before a large audience at an American Heart Association annual meeting and declared that his operation should no longer be performed because of the availability of effective antihypertensive drug therapy [15].

Similar attention was being given to various means of controlling the contribution of elevated lipid and cholesterol levels to the process of atherosclerosis, the leading cause of acute and chronic coronary heart disease. In addition to dietary control, both control of diabetes and weight management, and the development of the statin drugs contributed to more effective management of this strong risk factor [16].

\section{Socioeconomic Factors}

The rapidity with which the public and private hospitals in the urbanized areas of Los Angeles County developed up-to-date facilities for emergency care and identifying secondary medical undoubtedly contributed independently to mortality rates. Similarly, the expansion of care availability for follow-up care through federal, state and county funding sources contributed to post-acute care and long-term control of risk factors.

Somewhat paradoxically, the availability of better acute care and identification of discrete follow-up issues have reduced the need for acute care beds in public hospitals and when coupled with increased insurance resources in state and local agencies (supplemented by federal funds) overall hospitalization rates have declined.

Some attention has also been given to the general contribution of improved economic condition, living conditions and health care availability post World War II.

\section{Conclusions}

There is complexity in trying to parse all of the major contributors to the major decline in coronary disease death rates in Los Angeles County and the country as a whole, but it is clear that the development of coronary care units helped to usher in this new era of progress [17].

The assault on heart disease and high blood pressure continues, as it must, and no doubt will be supplanted by equal or greater emphasis on malignancy and other factors when the battle against heart disease as the leading cause of death is finally won.

\section{Acknowledgements}

The author wishes to thank Cassandra Pruitt for manuscript preparation and Loren Loeb, Ph.D., for providing the illustration graph from the National Center for Health Care Statistics.

\section{References}

[1] Keys, A. (1951) Bullen: Heart Association List of Risk Factors, John Hopkins 88:473. 
JAMA, 147, 1514. https://doi.org/10.1001/jama.1951.03670330006003

[2] Rosenbaum, J.B. and Hanson, D. (1954) CPR/DC Fibrillation. JAMA, 155, 1151.

[3] Criley, J.M., Blaufuss, A.N. and Kissel, J.L. (1976) Cough Induced Cardiac Compression. JAMA, 263, 1246. https://doi.org/10.1001/jama.1976.03270120022018

[4] Bearman, J.E., Berryman, G.H., Griggs, D.E. and Haywood, L.J. (1964) Sodium Heparin versus Warfarin in Acute Myocardial Infarction. Journal of the American Medical Association, 189, 555-562. https://doi.org/10.1001/jama.1964.03070070027007

[5] Wilbourne, M. (1961) The Coronary Care Unit: A New Approach to the Treatment of Acute Coronary Occlusion (Abstract). CIRC, 24, 1074.

[6] Haywood, L.J. (1967) Acute Myocardial Infarction in Los Angeles County. California Medicine, 107, 247-250.

[7] Lee, T.H. and Goldman, L. (1988) The Coronary Care Unit Turns 25. Annals of Internal Medicine, 108, 887. https://doi.org/10.7326/0003-4819-108-6-887

[8] Lown, B., Grampton, R.G. and DeSilva, R.A. (1978) The Energy for Defibrillation. NEJM, 298, 1252.

[9] Haywood, L.J., Harvey, G.A. and Kirk Jr., W.L. (1969) On-Line Digital Computer for EKG Monitoring in a Coronary Care Unit. Journal of the Association for the Advancement of Medical Instrumentation, 3, 165-169.

[10] Killip, T. and Kimball, J.T. (1967) Treatment of Myocardial Infarction in a Coronary Care Unit. American Journal of Cardiology, 20, 457. https://doi.org/10.1016/0002-9149(67)90023-9

[11] Swan, W., Donoso, R. and Marcus, H.S. (1971) Measurement of Cardiac Output by Thermo-Dilution in Man. American Journal of Cardiology, 27, 392. https://doi.org/10.1016/0002-9149(71)90436-X

[12] Forrester, J.S., Diamond, G. and Chattergee, K. (1976) Medical Therapy of Acute Myocardial Infarction by Application of Hemodynamic Subsets. New England Journal of Medicine, 295, 1356. https://doi.org/10.1056/NEJM197612092952406

[13] DeWood, M., Spores, J. and Notske, R. (1980) Prevalence of Total Coronary Artery Occlusion. NEJM, 309, 897. https://doi.org/10.1056/NEJM198010163031601

[14] Finnerty Jr., F.A. (1954) The Value of Rauwolfia serpentina in the Hypertensive Patient. American Journal of Medicine, 17, 629.

https://doi.org/10.1016/0002-9343(54)90022-4

[15] Smithwick, R.H. (1951) Hypertensive Cardiovascular Disease Effect of Thoracolumbar Splanchnicectomy on Mortality and Survival Rates. Journal of the American Medical Association, 147, 1611. https://doi.org/10.1001/jama.1951.03670340001001

[16] Pastemak, R.C., Braunwald, E. and Sobel, B.E. (1992) Acute Myocardial Infarction. Heart Disease, Eugene Braunwald, WB Saunders CO, 4th Edition, 1200-1291.

[17] Mozaffarian, D., Benjamin, A.S. and Arnett, D.K. (2015) Heart Disease and Stroke Statistics-2016 Update. A Report from the American Heart Association. Circulation, 132. 


\section{Appendix}

ำ ำ ำ

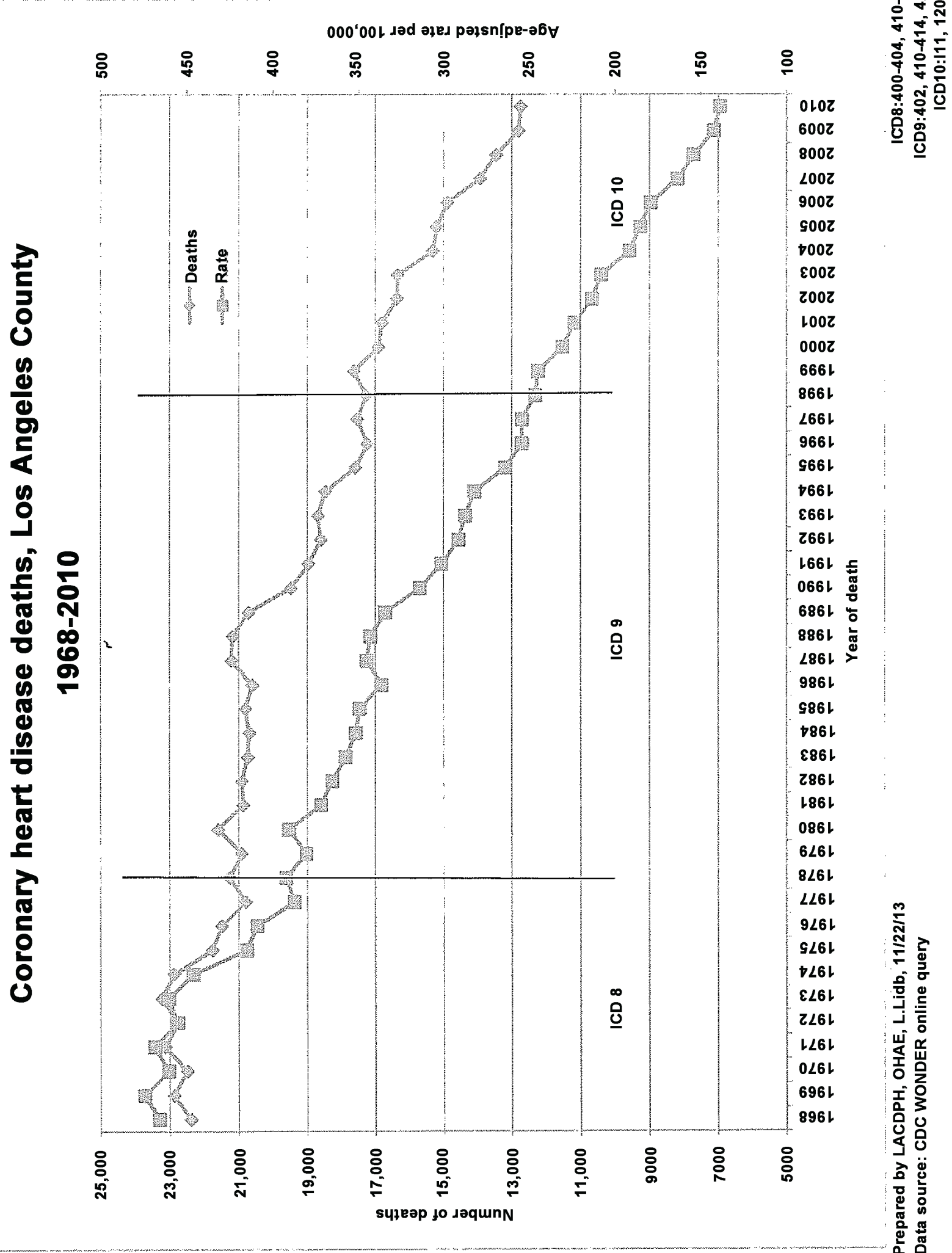

